\title{
RAILWAY RATIONALIZATION
}

\begin{abstract}
A LTHOUGH railway speeds in Great Britain are generally good, the average speed at which a traveller could accomplish a series of random journeys by rail is likely to prove very disappointing. No doubt, many passengers ask themselves if something better were not possible, but seeing no solution to the problem, accept the position as inevitable. That it is a state of affairs which can be improved by a rational system of reorganization, leading possibly to the doubling of the average speed, is the contention put forward by Mr. J. F. Pownall in a booklet entitled "New Railway Network Principles" (Birmingham: Cotterell and Co. 2s.). This contains the gist of the chapters of a book dealing with one of two projects relating to waterways and railways in Great Britain which have had to be set aside to await the advent of better days.

Now, however, is the time for such ideas to be broadcast so that when these better days come we may be prepared to make such changes in our present system as will restore the railways to the position they once held in the estimation of the public. The author has taken a journey of 2,342 miles, from one town to another and then to a third and so on, and finds from "Bradshaw" that the average speed works out at $16 \frac{1}{2}$ miles an hour. His method of improving this is based on an ideal network of equilateral triangles of 50 miles side, and along the sides of these triangles fast trains would start precisely at each hour and arrive 52 minutes later. This gives 8 minutes at each junction for changing if necessary. Slow, stopping trains would also run, taking about two hours for the same journey, and by their means a traveller starting from an intermediate station travels at about 25 miles per hour to the first junction, then on by
\end{abstract}

fast trains at 50 miles an hour, and lastly to an intermediate destination by a slow train at 25 miles per hour.

Turning then to the practical application of this ideal system, the author shows that by certain modifications of the present lines a workable system of railway operation can be developed so that the original series of journeys could be accomplished at $31 \frac{1}{2}$ miles an hour, or in a total time of 74 hours instead of 142 hours as planned from "Bradshaw". This remarkable saving of time is but one-the principal one - of many advantages of the system. Another is the simplicity of time-tables, since trains would always start from the junction stations precisely at the hour and from intermediate stations always at a fixed number of minutes after the hour.

The fast and slow trains referred to are in addition to the main line expresses, and thus, if any substantial part of a journey such as that described followed these main lines, a further saving of time is probable. A similar scheme is put forward for the improvement of goods traffic on the railways, but when the author suggests that the loading gauge should be made considerably larger than at present, he enters upon a phase the cost of which would almost certainly heavily outweigh the advantages it would confer. Many of his proposals are, however, quite feasible and only need a change of outlook from our present markedly conservative one. The new type of junction station, the standardization of trains, the co-ordination of rail and road services, and many other details deserve-nay, rather demandfrom us all very careful consideration and thought, for, when all is said, the scheme involves a revolutionary change of mind as to the place of railways in our mode of life.

\section{A.R.P. COMMUNICATION}

$\mathrm{W}$ P. WILSON describes in the Engineering Supplement to the Siemens' Magazine of November the A.R.P. telephone and signalling system, A.R.P. (No. 186) devised by Messrs. Siemens. One of the essentials of any system is the provision of a trustworthy method of giving the various signals required, and maintaining rapid communication between the personnel concerned. For obvious reasons it is not desirable for private A.R.P. organizations to use sound signals ; it is usual, therefore, to employ bells or buzzers and visual lamp signals of various types, communication being maintained by a suitable telephone system.

In some cases existing private telephone systems can be used or adapted to meet the conditions, but it is generally found that a separate system designed to meet the special conditions is the most desirable. This is particularly the case where large schemes are concerned. In such instances it is usually advisable to supplement any existing telephone system by an entirely separate emergency scheme in order to safeguard against the failure or destruction of the regular telephone system.

The mere knowledge of the existence of a reliable communication system greatly assists in dispelling feelings of isolation or panic on the part of the staff of the organization concerned. One of the essential things to consider in connexion with a communication system is the probable short time available for taking action after the receipt of a warning. This is particularly the case under the recent arrangements of the 'spotter' system. Communications include both telephone and signal systems, the former to provide complete control of the A.R.P. personnel, and the latter to indicate clearly to the whole staff the action to be taken.

The telephone system, which should be planned to meet individual requirements, should be easy to operate and also to repair. For most cases a simple system of magneto telephones is believed to be the best. Magneto telephones are self-contained units, each has its own ringing apparatus and its own battery for supplying the speaking current, thus eliminating the risk of breakdown due to the failure of a central battery. Further, two or more magneto telephones can be connected together at the control board, and they can then ring each other direct without the assistance of an operator. If the control board is put out of action the line wires can be quickly connected so that the telephones continue in service by means of code rings. This is not feasible with central battery sets. 